\title{
TÉCNICAS E DISPOSITIVOS PARA UM BANHO INTELIGENTE
}

\section{TECHNIQUES AND DEVICES FOR SMART BATH}

\author{
Recebido: 04/04/2016 - Aprovado: 15/06/2016 - Publicado: 30/06/2016 \\ Processo de Avaliação: Double Blind Review
}

\author{
Alex Sandro de Araújo ${ }^{1}$ \\ - Graduação em Tecnologia em Manutenção Industrial \\ FATEC-Osasco \\ alsajo@ig.com.br \\ Lucas Lemos Timm \\ Graduação em Tecnologia em Manutenção Industrial \\ FATEC Osasco \\ lucas-timm@hotmail.com \\ Simmer Luiz de Mello \\ Graduação em Tecnologia em Manutenção Industrial \\ FATEC - Osasco \\ sl.lucio@bol.com.br \\ Antonio Carlos Santos de Arruda \\ Mestre em Engenharia Elétrica pela USP \\ Professor da FATEC - Osasco \\ antonio.arruda@fatec.sp.gov.br

\section{Gilberto Paiva} \\ Mestre em Física pela USP \\ Professor da FATEC - Osasco \\ gilberto.dpaiva@fatec.sp.gov.br

\section{Raphael Garcia Moreira} \\ Mestre em Ciências no Programa de Engenharia Elétrica da Politécnica - USP \\ Engenheiro elétrico com ênfase em computação \\ Professor da FATEC-Osasco \\ raphaelgarciamoreira@gmail.com

\footnotetext{
${ }^{1}$ Autor para correspondência: Faculdade de Tecnologia do Estado de São Paulo, Rua Pedro Rissato, 30, Vila dos Remédios, Osasco - SP, Brasil - CEP 06296-220.
} 


\section{Carlos Alberto de Freitas}

Especialista em Administração Industrial

Engenheiro de Produção

Professo da Fatec-Osasco

Carlos.afreitas@fatec.sp.gov.br

RESUMO: O atual cenário observado nas fontes energéticas e hídricas do Brasil exige formas de uso mais controladas que garantam a sustentabilidade destes recursos. Nesse sentido, a proposta deste trabalho foi a de produzir resultados que possam ser rapidamente empregados pela sociedade de todas as classes sociais em um ambiente onde mais se concentra o consumo de água e energia: o box do banheiro. Foram desenvolvidas quatro estratégias que irão auxiliar o uso racional da água e energia. O primeiro consiste de uma intervenção sistêmica dos chuveiros domésticos visando reduzir o consumo de energia em até $75 \%$ além de reduzir a vazão de água, sem danificar a resistência elétrica. Uma segunda estratégia é o aperfeiçoamento de um trocador de calor para chuveiro que aproveita o calor da água rejeitada para o ralo para pré-aquecer a água que irá entrar no chuveiro, com aproveitamento de até $44 \%$. Como terceira estratégia, uma camada de material hidrofóbica foi depositada sobre as paredes internas do box do chuveiro, visando diminuir a retenção de sujeiras e resíduos nestas superfícies, que resultou na redução da necessidade de lavar este ambiente e, por fim, uma quarta estratégia consiste de um sistema que monitora a atividade do banho por meio da resistividade da água descartada no ralo, esta resistividade irá indicar se a pessoa ainda está tomando banho ou se está havendo desperdício, caso seja caracterizado o desperdício uma solenoide irá cortar o fornecimento de água do chuveiro. Os resultados obtidos foram aderentes com o projetado e o trabalho sugere que novos estudos podem ser feitos visando melhorar a eficiência energética e hídrica no local de banho.

Palavras-chave: Água; Energia; Sustentabilidade; Banheiro; Hidrofóbica.

ABSTRACT: The current scenario observed in the energy and water sources from Brazil requires more controlled forms of use to ensure the sustainability of these resources. In 
this sense, the purpose of this study was to produce results that can be quickly employed by the company of all walks of life in an environment where most concentrates the energy and water consumption: the bathroom stall. Four strategies that will assist the rational use of water and energy were developed. The first is a systemic intervention of domestic showers to reduce energy consumption by $75 \%$ and reduces the flow of water, without damaging the electrical resistance. A second strategy is the improvement of a heat exchanger to shower that takes advantage of the heat from the water rejected into the drain to preheat the water will get into the shower, with use of up to 44\%. As a third strategy, a layer of hydrophobic material has been deposited on the inner walls of the shower stall in order to reduce the retention of dirt and waste on these surfaces, resulting in reduction of the need to wash this environment and, finally, a fourth strategy is a system that monitors the activity of the bath through the resistivity of the water discharged into the drain, this resistivity will indicate whether the person is still bathing or is being wasted, if characterized waste one solenoid will cut the supply of water shower. The results were compliant with the designed and the work suggests that further studies can be done to improve energy efficiency and water in the bathing place.

Keywords: Water: Energy; Sustainability; Bathroom; Hydrophobic.

\section{INTRODUÇÃO}

O banheiro é indispensável para a vida moderna, tanto nas regiões urbanas quanto rurais, contudo, é neste local onde se encontram os maiores consumos doméstico de água e de energia (GHISI; FERREIRA, 2007). Com a crise hídrica e energética enfrentada em São Paulo, especialmente nos anos de 2014 e 2015, muitas iniciativas foram tomadas a fim de incrementar a eficiência do emprego de tais fontes, por outro lado, é necessário desenvolver técnicas e equipamentos simples que possam ser rapidamente aplicados pela população (MUTHUKUMARAN; BASKARAN; SEXTON, 2011). Existem propostas promissoras no sentido de minimizar o uso da água e da energia em banheiros (WILLI Set al., 2010), tais como painéis digitais que apresentam instantaneamente o consumo de água e energia consumida no banheiro, válvulas inteligentes, privadas a vácuo com alto performance, etc. 


\section{FUNDAMENTAÇÃO TEÓRICA}

Nos dias de hoje é extremamente importante a conscientização e o empenho nas relações homem e meio ambiente, pois atravessamos uma fase muito complicada onde os recursos da natureza vêm cada vez mais ficando extintos em nosso meio. Projetos educacionais e principalmente a conscientização assim como novas tecnologias são essenciais para contornamos o atual cenário de degradação.

\subsection{SUSTENTABILIDADE}

A sustentabilidade é o uso de recurso de modo a não prejudicar, ou minimizar o possível o desequilíbrio ambiental, assim poupando toda forma de vida ou comunidade que dependem desse ecossistema.

Uma medida bem interessante é ensinar cada família a calcular sua influência negativa sobre o meio ambiente (suas emissões) e orientá-las a proceder de forma a neutralizá-las, garantindo a sustentabilidade da família e contribuindo enormemente para a conservação do meio ambiente em que vivem.

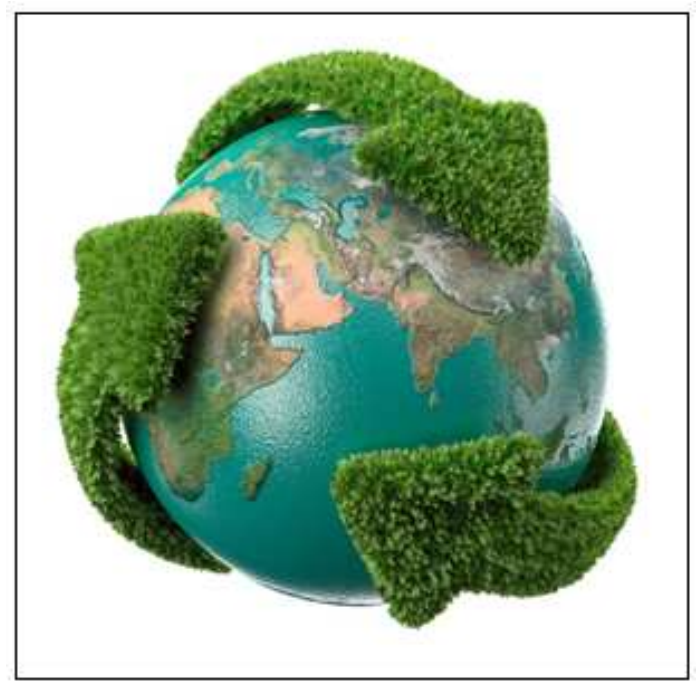

Figura 1 - Planeta Sustentável

(Fonte: blog.serbras.com.br)

Mas, como se

faz par calcular essas emissões? Basta calcular a energia elétrica consumida pela família; o número de carros e outros veículos que ela utilize e a forma como o faz e os resíduos que ela produz. A partir daí; cada família poderá dar a sua contribuição para promover práticas e procedimentos que garantam a devolução à natureza de tudo o que usaram. 
Assim, reduzindo-se os desperdícios, os despejos de esgoto doméstico nos rios e as demais práticas ambientais irresponsáveis; os danos causados ao meio ambiente serão drasticamente minimizados e a sustentabilidade dos assentamentos humanos e atividades econômicas de qualquer natureza estarão asseguradas.

Segundo a SEMAR (Secretaria Estadual do Meio Ambiente e Recursos Hídricos - 28/10/2010) estimular o plantio de árvores, a reciclagem de lixo, a coleta seletiva, o aproveitamento de partes normalmente descartadas dos alimentos como cascas, folhas e talos; assim como o desenvolvimento de cursos, palestras e estudos que informem e orientem todos os cidadãos para a importância da participação e do engajamento nesses projetos e nessas soluções simples para fomentar a sustentabilidade e a conservação do meio ambiente.

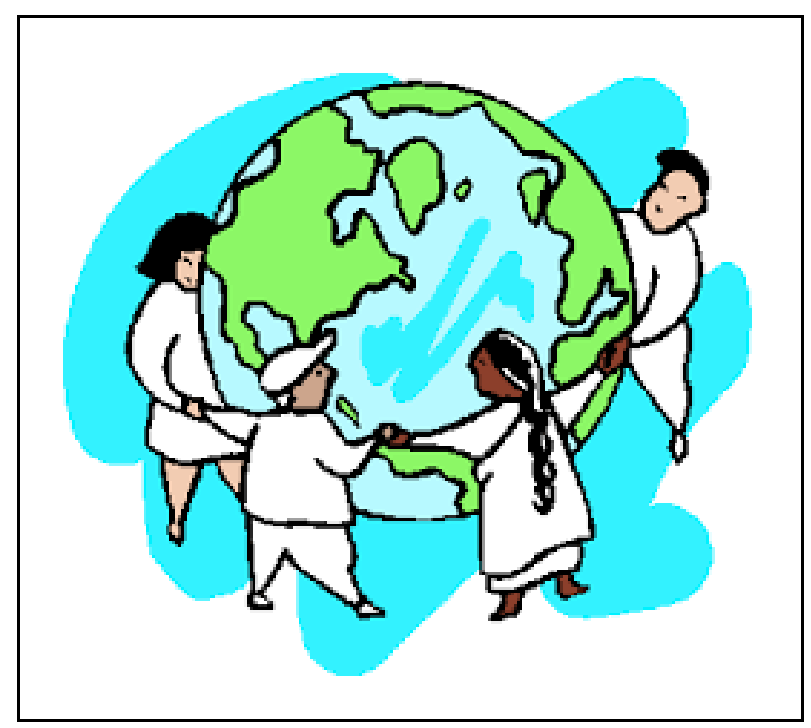

Figura 2 - Cuidando do Planeta (Fonte: sustentabilidade.com.br)

O grande marco para o desenvolvimento sustentável mundial foi, sem dúvida a Conferência das Nações Unidas sobre Meio Ambiente e desenvolvimento, realizada no Rio de Janeiro em Junho de 1992 (a Rio 92), onde se aprovaram uma série de documentos importantes, dentre os quais a Agenda 21, um plano de ação mundial para orientar a transformação desenvolvimentista, identificando, em 40 capítulos, 115 áreas de ação prioritária. 
A Agenda 21 apresenta como um dos principais fundamentos da sustentabilidade o fortalecimento da democracia e da cidadania, através da participação dos indivíduos no processo de desenvolvimento, combinando ideais de ética, justiça, participação, democracia e satisfação de necessidades. O processo iniciado no Rio em 92 reforça que antes de se reduzir a questão ambiental a argumentos técnicos, deve-se consolidar alianças entre os diversos grupos sociais responsáveis pela catalisação das transformações necessárias. Dentre alguns dos focos discriminados na Agenda 21, podemos destacar:

- $\quad$ Cooperação internacional;

- $\quad$ Combate à pobreza;

- Mudança dos padrões de consumo;

- Habitação adequada;

- Integração entre meio ambiente e desenvolvimento na tomada de decisões;

- $\quad$ Proteção da atmosfera;

- Abordagem integrada do planejamento e do gerenciamento dos recursos terrestres;

- Combate ao desflorestamento;

- Manejo de ecossistemas frágeis: a luta contra a desertificação e a seca;

- Promoção do desenvolvimento rural e agrícola sustentável;

- $\quad$ Conservação da diversidade biológica;

- Manejo ambientalmente saudável dos resíduos sólidos e questões relacionadas com os esgotos;

- Fortalecimento do papel das organizações não governamentais: parceiros para um desenvolvimento sustentável;

- Iniciativas das autoridades locais em apoio à Agenda 21;

- A comunidade científica e tecnológica;

- Fortalecimento do papel dos agricultores;

- Transferência de tecnologia ambientalmente saudável, cooperação e fortalecimento institucional;

- A ciência para o desenvolvimento sustentável; 
- Promoção do ensino, da conscientização e do treinamento.

\section{METODOLOGIA}

\subsection{OBJETIVOS DO PROJETO}

O objetivo geral deste trabalho é desenvolver quatro estratégias para prover maior economia de água e energia elétrica dentro de um banheiro. Tais estratégias consistem:

- Intervenção no chuveiro tradicional;

- Configuração do recuperador de calor doméstico;

- $\quad$ Aplicação de superfícies hidrofóbicas;

- Deteç̧ão de resíduos na água rejeitada visando detectar o fim do banho.

\subsubsection{OBJETIVOS ESPECIFICOS}

- Empregar uma técnica de reduzir a vazão de água e potência nominal de um chuveiro sem afetar seu bom funcionamento;

- Reaproveitar o calor da água rejeitada pelo ralo para pré-aquecer a água que vem da rua antes de ser aquecida pelo chuveiro por meio de um trocador de calor de baixo custo;

- Aplicar uma camada hidrofóbica sobre as paredes internas do box do banheiro afim de evitar que seja necessário lavá-las diariamente devido a incrustação de resíduos provenientes do banho;

- Desenvolver um dispositivo que detecta quando a pessoa está com o registro de água do chuveiro aberto sem estar se ensaboando ou se enxaguando, ou seja, o objetivo deste dispositivo é detectar o fim do banho;

- Desenvolver um dispositivo que meça a vazão de água do chuveiro e que contabilize a quantidade de água consumida no banho.

\subsection{JUSTIFICATIVA}

A água potável e a energia elétrica são recursos que juntos constituem a bases fundamentais para a sobrevivência nas grandes cidades, a escassez de um ou ambos destes recursos resulta em uma crise que afeta diversos setores da sociedade (DI GIULIO, 2014). 
O melhor aproveitamento dos recursos hídricos que representam inclusive a base da geração de energia elétrica de nosso país, a construção de mais represas, as melhorias no gerenciamento de mananciais, tornar mais eficiente o tratamento das águas são, sem dúvida, responsabilidades do Estado. Contudo, a sociedade é corresponsável e deve procurar meios de consumir de maneira eficiente a água e a energia elétrica. A Educação Ambiental e o entendimento da sustentabilidade devem fazer parte do desenvolvimento consciente da sociedade (RUFFINO et al., 2012).

Entre os locais onde mais se consome água e energia é o local de banho, ou seja, debaixo do chuveiro, estudos globais reportam que $42 \%$, em média, do consumo de água de uma residência concentram-se no chuveiro (MAKKI et al., 2013). Também existe um grande desperdício de energia térmica no local de banho, uma vez que água aquecida (a custo de grande energia) termina por ser rejeitada no ralo sem nenhum outro emprego, muitas pesquisas começam a investigar maneiras de recuperar esta energia (RAMADAN; KHALED, 2014).

Por apresentar técnicas e dispositivos que possam ser rapidamente aplicados pela sociedade com o objetivo de racionalizar o consumo de água e energia e assim garantir a sustentabilidade dos recursos, este trabalho é fortemente justificado.

\subsection{MÉTODO E PROCEDIMENTO}

Pesquisando formas e métodos de metodologia entendemos que esse projeto em particular está mais adequado ao método comparativo, que por sua vez utiliza os dados obtidos e os comparam podendo assim tirar uma conclusão posteriormente.

Muitos dos resultados adquiridos foram conseguidos através de pesquisas insistentes, testes e modificações conforme o progresso do projeto. As intervenções diárias nos levaram a conhecer mais profundamente o protótipo eliminando qualquer tipo de duvida a respeito da funcionabilidade e desenvolvimento.

Vale salientar que no decorrer do projeto surgiram algumas perguntas interessantes onde estaremos mitigando esses assuntos no capitulo 3, pesquisaremos custo/beneficio na construção ou reforma de um banheiro convencional para o banheiro inteligente em residências, apartamentos, etc. 
Comparativo de valores a serem feitos das seguintes situações:

- Implantação do banheiro em uma casa de alvenaria;

- Implantação do banheiro em um apartamento;

- Reforma e inclusão em uma casa de alvenaria;

- $\quad$ Reforma e inclusão em um apartamento;

- Custo/ Beneficio Chuveiro elétrico x chuveiro a gás;

- Custo/ Beneficio Chuveiro elétrico x energia solar;

\subsection{MÉTODOS DE PESQUISA PARA RECURSOS NECESSÁRIOS}

O projeto de um box de banheiro "inteligente" e conceitual visando o desenvolvimento de técnicas que incrementem a eficiência da água e energia em um banheiro foi desenvolvido em projeto de baixo custo, que irá empregar materiais como:

- $\quad 15$ metros de perfil de ferro $30 \mathrm{~mm}$ x $30 \mathrm{~mm}$;

- $\quad$ Chapas de Policarbonatos;

- $\quad$ Chapas de madeira compensada;

- Tubos e registros hidráulicos para aplicação doméstica;

- Dois Chuveiros convencionais;

- Uma placa do Arduino;

- Dois Disjuntores e duas fontes de 12V;

- $\quad$ Uma solenoide e um leitor de vazão;

- Uma bomba de D’agua;

- Uma boia eletrônica;

- $\quad$ Duas lâmpadas de led;

- Uma bomba pressurizadora de água;

- $\quad$ Fios, tomadas, interruptores, plugs, dobradiças, puxadores, etc.

Os dados descritos nesse projeto partiram de várias fontes de pesquisa, como por exemplo de livros e artigos e documentados, pesquisas através de sites, outros resultados adquiridos foram através de experimentos e testes visando sempre um condição adequada ao que foi sugerido no objetivo.

Tendo em vista que através de estudos e pesquisas tínhamos presumidos os resultados de alguns fatores onde depois foi concretizado na pratica, consequentemente, 
aumentando as nossas expectativas nos dando uma visão mais abrangente do que seria esse projeto, abrindo portas para outras pesquisas futuras.

A sustentabilidade dos recursos energéticos e hídricos constitui o foco dos temas que serão considerados a seguir.

\section{APRESENTAÇÃO E ANALISE DE RESULTADOS}

O melhor aproveitamento dos recursos hídricos que representam inclusive a base da geração de energia elétrica de nosso país, a construção de mais represas, as melhorias no gerenciamento de mananciais, tornar mais eficiente o tratamento das águas são, sem dúvida, responsabilidades do Estado. Contudo, a sociedade é corresponsável e deve procurar meios de consumir de maneira eficiente a água e a energia elétrica. A Educação Ambiental deve fazer parte do desenvolvimento consciente da sociedade (RUFFINO et al., 2012).

Entre os locais onde mais se consome água e energia é o local de banho, ou seja, debaixo do chuveiro, estudos globais reportam que $42 \%$, em média, do consumo de água de uma residência concentram-se no chuveiro (MAKKI et al., 2013). Também existe um grande desperdício de energia térmica no local de banho, uma vez que água aquecida (a custo de grande energia) termina por ser rejeitada no ralo sem nenhum outro emprego, muitas pesquisas começam a investigar maneiras de recuperar esta energia (RAMADAN; KHALED, 2014).

\subsection{SITUAÇÃO ATUAL}

Chuveiro ou duchas de resistência elétrica são os equipamentos para banho mais usados no Brasil, cerca de 99,6\% de acordo com o Plano Nacional de Eficiência Energética do MME.

O chuveiro é um dos equipamentos elétricos domésticos que mais consome energia, em torno de 21\% (GHISI; GOSCH; LAMBERTS 2007; PAPST et al., 2005), e também é o ponto de maior consumo doméstico de água (ROCHA et al., 1999).

Outros pontos de consumo de energia podem ser observados nas Tabela 1 e Tabela 2. 


\begin{tabular}{|c|c|c|c|c|c|c|c|c|}
\hline \multicolumn{2}{|c}{ Aparelho } & \multicolumn{2}{c}{ Verão } & \multicolumn{2}{c}{ Inverno } & \multicolumn{2}{c|}{ Média } & \multicolumn{2}{c|}{ Aparelho } & \multicolumn{2}{c|}{ Verão } & \multicolumn{2}{c|}{ Inverno } & Média \\
\hline Refrigerador & $32 \%$ & $32 \%$ & $32 \%$ & & Televisor & $7 \%$ & $7 \%$ & $7.0 \%$ \\
\hline Chuveiro & $18 \%$ & $22 \%$ & $20 \%$ & $\begin{array}{c}\text { Aparelho de } \\
\text { Som }\end{array}$ & $4 \%$ & $7 \%$ & $5.5 \%$ \\
\hline Ar Cond. & $16 \%$ & $2 \%$ & $9 \%$ & Ferro & $3 \%$ & $4 \%$ & $3.5 \%$ \\
\hline Iluminação & $9 \%$ & $13 \%$ & $11 \%$ & & Lava Roupa & $2 \%$ & $3 \%$ & $2.5 \%$ \\
\hline \hline Freezer & $9 \%$ & $9 \%$ & $9 \%$ & & Microondas & $0 \%$ & $1 \%$ & $0.5 \%$ \\
\hline
\end{tabular}

popular na cidade de São

7).

\section{Pontos de utilização de \\ Consumo diário por habitação \\ Percentual do uso no \\ água \\ (L/ habitação.dia) \\ consumo diário $(\%)$}

\begin{tabular}{|c|c|c|}
\hline Chuveiro & 238 & 55 \\
\hline Pia de cozinha & 80 & 18 \\
\hline Lavadora de roupas & 48 & 11 \\
\hline Lavatório & 36 & 8 \\
\hline Ba & 24 & 3 \\
\hline Tanque & 11 & 100 \\
\hline \hline T O T A L & 437 & 3 \\
\hline
\end{tabular}

- na cidade de São Paulo

E como já citado, outros estudos apontam resultados semelhantes dependendo das características meteorológicas, ambientais e culturais (MAKKI et al. 2013).

Desta forma, é de interesse público que estudos e melhorias tecnológicas para a redução do consumo de água e energia, especificamente em chuveiros sejam desenvolvidos. 


\subsection{PROBLEMAS MENSURAVEIS}

O maior problema encontrado é a desperdício de água 75 litros diários, (segundo dados do INMETRO) por pessoa, ou seja, 46,7\%, sem contar todo o potencial térmico desperdiçado pelo ralo. Se gasta assim energia elétrica e recurso hídrico com apenas uma finalidade sendo que encontramos outras utilidades para esta água que escorre via ralo.

Abaixo segue a relação de gasto de energia elétrica e consumo de água residencial.

Tempo do Banho em minutos - Custo por dia

\begin{tabular}{r|r|r|r|r|}
\hline Potência do Chuveiro (Watts) & $\mathbf{1 0}$ & $\mathbf{1 5}$ & $\mathbf{2 0}$ & $\mathbf{3 0}$ \\
\hline 3200 & $\mathrm{R} \$ 0,33$ & $\mathrm{R} \$ 0,50$ & $\mathrm{R} \$ 0,66$ & $\mathrm{R} \$ 0,99$ \\
\hline 4500 & $\mathrm{R} \$ 0,47$ & $\mathrm{R} \$ 0,70$ & $\mathrm{R} \$ 0,93$ & $\mathrm{R} \$ 1,40$ \\
\hline 5500 & $\mathrm{R} \$ 0,57$ & $\mathrm{R} \$ 0,85$ & $\mathrm{R} \$ 1,14$ & $\mathrm{R} \$ 1,71$ \\
\hline 6000 & $\mathrm{R} \$ 0,62$ & $\mathrm{R} \$ 0,93$ & $\mathrm{R} \$ 1,24$ & $\mathrm{R} \$ 1,86$ \\
\hline 7500 & $\mathrm{R} \$ 0,78$ & $\mathrm{R} \$ 1,16$ & $\mathrm{R} \$ 1,55$ & $\mathrm{R} \$ 2,33$ \\
\hline
\end{tabular}

Tempo do Banho em minutos - Custo no final de 30 dias

\begin{tabular}{r|r|r|r|r|}
\hline Potência do Chuveiro (Watts) & $\mathbf{1 0}$ & $\mathbf{1 5}$ & $\mathbf{2 0}$ & $\mathbf{3 0}$ \\
\hline 3200 & $\mathrm{R} \$ 9,92$ & $\mathrm{R} \$ 14,88$ & $\mathrm{R} \$ 19,84$ & $\mathrm{R} \$ 29,76$ \\
\hline 4500 & $\mathrm{R} \$ 13,95$ & $\mathrm{R} \$ 20,93$ & $\mathrm{R} \$ 27,90$ & $\mathrm{R} \$ 41,85$ \\
\hline 5500 & $\mathrm{R} \$ 17,05$ & $\mathrm{R} \$ 25,58$ & $\mathrm{R} \$ 34,10$ & $\mathrm{R} \$ 51,15$ \\
\hline 6000 & $\mathrm{R} \$ 18,60$ & $\mathrm{R} \$ 27,90$ & $\mathrm{R} \$ 37,20$ & $\mathrm{R} \$ 55,80$ \\
\hline 7500 & $\mathrm{R} \$ 23,25$ & $\mathrm{R} \$ 34,88$ & $\mathrm{R} \$ 46,50$ & $\mathrm{R} \$ 69,75$ \\
\hline
\end{tabular}

Tabela 4 - Consumo de água residencial

(Fonte: www.inmetro.gov.br/consumidor/tabelas.asp) 
A seguir a figura abaixo mostra em forma de gráfico o consumo médio de água de uma residência:

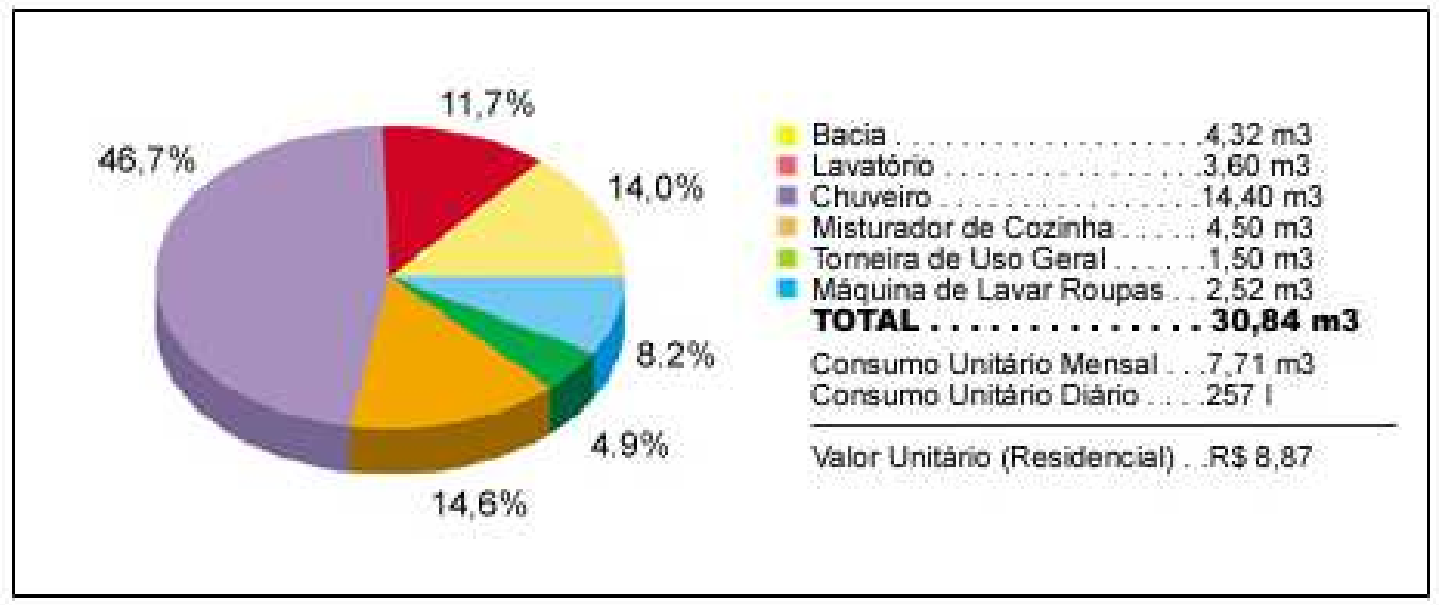

Figura 3 - Consumo de Água no Banheiro e Cozinha

(Fonte: www.inmetro.gov.br/consumidor/tabelas.asp)

Outro problema é que todos os chuveiros são projetados para trabalhar na faixa de 220 Volts e com uma determinada pressão é que ocorre a abertura do diafragma onde se inicia o banho. Experimentos mostram que se alterarmos está pressão que está diretamente ligada ao inicio do ciclo de banho, fazendo com que o chuveiro libere a água em menor pressão, será necessário apenas $110 \mathrm{v}$ para aquecimento da água em menor volume. Assim reduzira o consumo em $75 \%$ tanto de energia elétrica como de água, segundo testes realizados com o protótipo.

Outro quesito muito importante é referente a higienização do box e paredes do banheiro, onde há acumulo de resíduos provenientes do banho, forçando assim uma limpeza diária, onde após ser aplicado a superfície hidrofóbica essa limpeza será feita uma vez por mês.

Para finalizar, o maior responsável pelo desperdício de agua, são os banhos demorados, onde já houve remoção total dos resíduos corporais e mesmo assim os indivíduos continuam demorando no banho sem outra função a se exercer. Com a escassez da água e com a crise hídrica o desperdício não afeta apenas em gastos com consumo, mais também, compromete as gerações futuras e o meio ambiente pela falta de agua potável já notada nos dias de hoje. 


\subsection{SITUAÇÃO PROPOSTA}

Nossa proposta é desenvolver quatro estratégias para prover maior economia de água e energia elétrica dentro de um banheiro. Tais estratégias consistem: na intervenção no chuveiro tradicional, na configuração do recuperador de calor doméstico, na aplicação de superfícies hidrofóbicas e detecção de resíduos na água rejeitada visando detectar o fim do banho.

Por isso desenvolvemos o projeto de um box de banheiro "inteligente" e conceitual visando a aplicação de técnicas que incrementem a eficiência da água e energia em um banheiro. Foi desenvolvido em projeto de baixo custo, que irá empregar materiais como: acrílico, chapas de madeira compensada, tubos hidráulicos para aplicação doméstica, chuveiro, uma placa do Arduino, uma bomba de máquina de lavar roupas e dois chuveiros simples com regulagem de temperatura para frio, morno e quente. A seguir mostraremos o protótipo realizado com o desenho do projeto proposto.

Com a idéia da criação de um banheiro, foi necessário pensar em um ambiente similar para aplicar as intervenções e implantar os dispositivos. Criou-se a partir daí um layout em uma espécie de croqui. Com o auxilio do software (Google Sketchup) criamos as formas e iniciou-se a nova etapa, a construção.

Efetuamos levantamento de materiais, a princípio os ferros, e a partir da compra foi necessário soldar estes materiais. Após efetuado a soldagem da estrutura, começamos a lixar e consequentemente pintar a mesma. Seguiu-se o processo de pesquisa e levantamento dos revestimentos laterais (madeira e policarbonato).

\section{CONSIDERAÇÕES FINAIS}

A intervenção do chuveiro elétrico convencional no sentido de conectar uma resistência com tensão nominal de 220 Volts em 110 Volts e reduzir a vazão mostrou ser uma alternativa viável com potencial de ser amplamente empregado pela sociedade, uma vez que um banho com economia de $75 \%$ de água e energia utilizado por toda sociedade pode contribuir significativamente com as atuais questões de sustentabilidade tão necessárias para o cenário nacional e mundial. A intervenção do diafragma para fazer com que a resistência elétrica seja acionada com baixa vazão mostrou-se ser bastante simples. 
O recuperador de calor apresentou eficiência máxima de 44\%, porém em condições específicas de baixa vazão, sendo que na vazão nominal dos chuveiros utilizados apresentou eficiência de $25 \%$ frente aos sistemas comerciais que atingem $34 \%$ de eficiência.

O tratamento hidrofóbico aplicado sobre as paredes de acrílico utilizados para construir o box não se mostrou tão eficiente quanto ao tratamento hidrofóbico em vidro, isto ficou evidenciado pela maior retenção de resíduos de maisena nas paredes do acrílico.

A detecção de fim de banho ainda não foi totalmente equalizada no sentido de se obter os valores instantâneos de resistividade da água em diferentes condições, ou seja, foi observado que concentrações de cloro e diferentes detergentes influenciam a resistividade da água de maneira bastante significativa, o que significa que as medições não são totalmente estáveis e repetitivas.

\section{PERSPECTIVAS FUTURAS}

Como perspectivas futuras é sugerido para o presente trabalho que uma tubulação com aletas seja utilizada para melhorar a eficiência do recuperador de calor, uma vez que as aletas irão contribuir com o aumento da área de troca da tubulação.

Uma nova resina hidrofóbica deverá ser pesquisada e testada para se obter melhores resultados com o acrílico, ou as paredes do box desenvolvido para o presente trabalho deverão ser trocadas por vidro.

Um novo sistema de medição de resistividade de água deverá ser desenvolvido. Se for mantida a idéia de medir resistividade, é recomendado que a medição seja feita um uma tensão maior entre os eletrodos, contudo, o sistema pode ser testado com um medidor de $\mathrm{Ph}$, nesse caso, novos testes deverão ser realizados visando caracterizar água limpa e água contendo resíduos de banho.

Espera-se que uma cartilha possa ser impressa com linguagem simples, e que o governo do Estado São Paulo junto ao Centro Paula Souza possa distribuir para todas as classes sociais que visam economizar água e energia:

- Um chuveiro que funciona com $1 / 4$ da vazão de água normal e que economiza $75 \%$ de energia durante o inverno; 
- Um recuperador de calor que aproveita a energia (calor) da água que vai pelo ralo durante o banho;

- Um sistema de auto limpeza das paredes do banheiro que fará com que deixe de ser necessário lavar e esfregar as paredes do box, economizando dessa forma a água que seria empregada;

- Um sistema que detecta o fim de banho, quando a pessoa deixa de se ensaboar e repassar durante o banho.

\section{REFERÊNCIAS}

ABINEE. A Voz da Indústria Elétrica e Eletrônica do Brasil. Disponível em <http://www.abinee.org.br/programas/50anos/public/45anos/index.htm> Acesso em 13 abr. 2015.

ASSIS, O. B. G.; DE BRITTO, D. Determinação das frações polares e apolares da superfície de filmes biopoliméricos por medida estática de ângulo de contato. Embrapa Instrumentação-Artigo em anais de congresso (ALICE). In: SIMPÓSIO NACIONAL DE INSTRUMENTAÇÃ̃O AGROPECUÁRIA, 2014, São Carlos, SP Anais do SIAGRO: ciência, inovação e mercado 2014. São Carlos, SP: Embrapa Instrumentação, 2014. p. 371374. Editores: Carlos Manoel Pedro Vaz, Débora Marcondes Bastos Pereira Milori, Silvio Crestana, 2015.

DI GIULIO, G. M. A look at the local sphere: reflecting on climate change and cities. Ambiente \& Sociedade, v. 17, n. 3, p. 279-284, 2014.

FERREIRA, L. M. V. Revestimentos hidrofóbicos. 2013.

GHISI, E.; FERREIRA, D. F. Potential for potable water savings by using rainwater and greywater in a multi-storey residential building in southern Brazil. Building and Environment, v. 42, n. 7, p. 2512-2522, 2007.

GHISI, E.; GOSCH, S.; LAMBERTS, R. Electricity end-uses in the residential sector of Brazil. Energy Policy, v. 35, n. 8, p. 4107-4120, 2007.

HIGA MOREIRA, L. H.; MOREIRA, R. Padrão de geometria fractal termodinamicamente estável disposto especificamente sobre superfícies metálicas de alumínio (al) ou cobre (cu) e empregado contra a formação e adesão de gelo e de ação protetiva à biocorrosão. BRA. Patent n. PI 1101703-1 A2, 20 Abr. 2011. 